\title{
The relationship of psychological hardiness with work holism
}

\author{
Mohamad Khaledian ${ }^{1, *}$, Banafshe Hasanvand ${ }^{1}$, Sohrab Hassan Pour ${ }^{2}$ \\ 1'Department of Psychology, Payame Noor University, PO BOX 19395 - 3697 , \\ Lashkarak Road, Tehran, Islamic Republic of Iran \\ ${ }^{2}$ Ghorveh Branch Islamic Azad University, Ghorveh, Islamic Republic of Iran \\ E-mail address: mohamad_khaledian22@yahoo.com
}

\begin{abstract}
Background and Aim: Present research intends to investigate relationship of psychological hardiness with work holism among high school teachers. Methods: The under study society includes all male and female high school teacher in Ghorveh city in the academic year 2012-2013. Using simple random sampling method, a sample size of 100 male and female teachers was selected. To collect data, Kobassa Psychological Hardiness Questionnaire and Aghabeigi Workaholics Questionnaire were employed. To analyze the data, descriptive statistics (frequency, percentage, mean and standard deviation) and inferential statistics (t-test and regression analysis) were used. Results: The findings indicated that there is negative and significant relationship between the variables psychological hardiness and work holism. In addition, there is association between gender and psychological hardiness and between gender and work holism, also the constituents of psychological hardiness (commitment, control and challenge) are able to predict work holism.
\end{abstract}

Keywords: psychological hardiness; work holism; gender

\section{INTRODUCTION}

Psychological hardiness is one of the elements which play a basic role in man's life quality and to create a balance among different dimensions of it .People who have low hardiness will hurt more by harmful elements in long term while people with high hardiness apparently have natural or acquirable security against the stressfulelements. Hardiness is the ability to understand the external conditions accurately and to make a desirable decision about oneself (Jomhari, 2002). Kobasa (1979) introduce the hardiness as a complicated personal characteristic which is formed by three constituents: challenge, control and commitment which are supposed as a set acting as mediators to mediate stress effect as the recognition situation are changing and the stressful facts of life are decreasing (Sabri and Abdkhodai, 2010). Hardiness is mainly relates to the adjustment and positive agreement encountering problems and difficulties (Issacson, 2002). Researchers believe that hardiness and vulnerability are two opposite poles of a same continuum (Fergus and Zemmerman 2005). Other researchers studied common features in people with hardiness includes: higher self-ruling, independency, sympathy, job commitment, endeavor, good problem, solving skills and good relationship with colleagues 
(Issacson, 2002). Kobasa and Maddi (1982) state that people are very resistant to the mental pressure and under the stressful situations not only don't hurt mentally but also they welcome them and believe that these situations are necessary for their development in life. Moreover, their studies about companies and graduated students showed that people who have a harden personalities will experience less mental pressure and they will not be threat by mental pressure (Kobasa and Maddi 1982). Researchers indicated that hardiness has a positive relationshipwith physical and mental disorder (Brooks 2003). Considering hardiness as a acquirable feature not mainly an inherent one (lambert 2007). Learning hardiness increase commitment, control and challenge rates, the effects of each separately or in combination can decrease the rate of recognized stress (Nasiri, 2010). Kobasa (1979) believes that it can enforce person ability to control situation ,to commit duties and to encounter events .Various studies have shown that hardiness has a positive relationship with people mental health (Maddi and khoshaba, 1994), it decrease stress (Shapperand ;Kashani 1999) and that hardiness has a positive relationship with people physical and mental health (Florian et al 1995).

The results of king et al; (1998) showed that people with hardiness evaluate unpleasant situations in a challenging manner than threatening one and have more commitment to themselves and their works and experience more sense of control in their lives. Kobasa (1979) has integrated three attributes:commitment, control and challenge all of which have originated from the existing philosophy. She has described hardiness as a shield against diseases (Jomhari, 2002).

This is one of the main aspects of the personal control "personal efficiency". This concept has been presented by Albert Bandura (1997), people who have this characteristic believe that they can do everything successfully (Majidian, 2004). The challenging people serve life changes as challenges or opportunities to development not as limitations or threats (Kobasa 1979). In addition, people with hardiness undergo less physical erosion in stressful conditions (Majidian, 2004). Work holism forms a great deal of man's life as well as work engages people in itself both physically and cognitively. However, the business turbulent world exerts numerous pressures on the business owners. Today organizations are dwindling in size and rebuilding that increase expectations and working demands and also it increase working hours (Schaufeli; et al; 2009). The term work holism has been presented first by Oates; 1971. He described this term as an uncontrollable need or obligation and driven to work continuously.

This definition involves two constituents:extreme work, extreme tendency; to spend more time to work than what the organization expects them to achieve its goals. The later indicates that work holists always and permanently think about work, even when they are not at work. In other word, work holist's mind usually engage in affaires relateto the work. These two compartments as the behavioral and cognitive elements of work holism point to the root of the work holism that is just consistent with the alcoholism (Oates 1971). One of the job concepts that have been presented in academic and organizational environments since 1970s is "work holism". Some researchers equalize work holism with other types of addiction and draw it with unhappy, sad or sensitive forms that person cannot do his work best and cause some problems to his colleagues too (Agha Beigi 2007). It is believed that work holists do work more than what is expected and do more efforts in a way that ignore their lives out of their job. Therefore it should be mentioned that the most evident feature of work holists is that they work more than what is necessary ( Buelens and Palman 2004). In general, work holism is defined as spending a considerable amount of time to work; that is continuous cognitive engagement along with preferring work during leisure time. (snir and Zohar 2008). To differentiate overworking results from correct planning and enough energy, theirdiscrepancies can be considered People who overwork do work as an essential thing and sometimes interpret it as a satisfying duty but work 
holists consider their work as a secure shelter by which they can avoid the unwanted commitments and feelings out of the work.

They know how and when attend home beside their families and friends completely and participate in its programs, work holists allow their work to have the maximum degree of importance in their lives. They often make commitments because of their work necessities, also people who over work can lose their enthusiasm to work but work holists cannot. Their minds engage in work even when they are at the exercising or recreational activities. These people engage their minds in working problems (Ahmadi et al 2010). Work holism is an unsatisfying kind of need to work during which the following indications are remarkable: like other addicts these people underestimate their working hours and ignore the overall time that they engage themselves in problems relate to the work at home or weekends.

These people ignore their spouse and children needs and serve their complaints as seeking excuse or demanding. Depression: Totally, these people don't feel excitement and liveliness. Reality distortion: In many cases, these patients are actually unaware of what they are doing and think that their unreasonable reactions are reasonable. Reduced self-confidence: Despite remarkable economic successes, these people apparently are powerful and self-confined but mentally they are unstable and weak which is need to control. This is another defending reaction of these people who want to satisfy their absence with excuse seeking when they are attendant. As a satisfactory reaction they are oversensitive to what has happened at home during their absences. Unfortunately, they analyze problems pessimistically (Snir and Harpaz 2006). Scott et al; (1997) also identified three models of workholism include: radical drive (scrupulous), perfectionism and prosperous. In their opinion work holists have a high degree of scruple, stress and anxiety.

Their work cause physical and mental problems, they have little satisfaction of their job and lives and their job performance are low. Perfectionist work holists have high level of stress and physical or mental problems, they have hostile and inefficient interrelationships, they have more arbitrary absence and also they have lower job satisfaction and performance. Finally, prosperous work holists have lower life and job satisfaction, physical and mental health, job performance and high organizational citizenship behaviors and lower stress and arbitrary service absence. Regarding the typology of work holism by Spence and Robins (1992) work holism is characterized based on the amount of these three constituents: Feeling of being driven to work, work involvement and work enjoyment. In work holists the rate of feeling of being driven to work is high, they have very high tendency to work but they don't enjoy it. In contrast, people who are keen to work will engage in it while they feel enjoyment and don't have an extreme drive. Moreover, they found that work holists experience higher job stress than others. Work holism can have different effects on people psychological and physical health and their relatives. The most common consequences of the work holism is to create a high level of job stress and family-work contradiction; Although the following cases can be mentioned: Increase health threatening indications, job elimination, problems in group working, avoid family relationships, communication problems, low life satisfaction, lack of leisure time enjoyment( Piotrowski and Vodanovich, 2008). However, there have been a few internal and external researches in this area and the author points to some researches in which two concepts of hardiness and addiction are presented as it was specified that work holism itself is a subconcept of addiction in its general form.Snir and Harpaz (2006) suggested that the probability of men works holism is more than women. Mohammad talebi (2008) in has study show the relationship between the organizational culture and work holism, Asgari, Mostafa (2002) has studied the relationship between hardiness and attachment style with the preparation for addiction that he obtained a negative and significant correlation between the hardiness and attachment with 
tendency to addiction. Kobasa et al (1982) state that people with hardiness had higher level of job satisfaction, low pressure at work environment and high quality of life compared to the people with low hardiness. Also,the rate of hardiness in men is more than women. Jomhari (2002) has examined the relationship between hardiness and tendency to depression and anxiety among male and female students from Tehran University.

Results showed that there is a reverse relationship between hardiness and tendency to depression and anxiety. Rash et al (1995) in his study showed that hardiness has a negative relationship with mental stress at work and it has a positive relationship with job satisfaction (Izakian, 2001). Maddi et al (1996) in his research showed that hardiness has a negative correlation with drug addiction, alcohol in the past and present. Ahadi et al, (2008) in his research studied the rate of hardiness in medical specialized assistances concluded that there is a positive correlation between hardiness and marriage and the mean score of hardiness in married people was $65 / 1 \pm 10 / 93$ and in unmarried ones it was $61 / 8 \pm 11 / 31$. In this research he found that there is a significant difference between male and females such that the mean and the standard deviation from the male and female hardiness score was $(11 / 15,64 / 7),(10 / 86$, $62 / 2$ ) respectively. The objective of this research is to investigate the relationship between hardiness with work holism high school teachers in the academic year of $2012-2013$. The main assumption of the research is to examine the significant relationship between hardiness and the rate of the work holism.

\section{METHODOLOGY}

Research plan: The present study is a descriptive research which is includes 250 (145 male and 105 female) high school teachers of Ghorveh city working in the academic year of 2010-2011. According to the Kukrun formulation 100 (50 male and 50 female) was selected as the sample size using simple random method. Among male teachers 28 teachers or $56 \%$ were married and 22 ones or $44 \%$ were unmarried and among females $30 \%$ were unmarried and 70 $\%$ were married. We send them questionnaires as below:

The work holism measurement questionnaire: Work holism rate questionnaire had been presented by Agha Beigi (2007) and includes 30 questions. It uses Likert scale to the test scoring $(1=$ never, $2=$ sometimes, $3=$ often, $4=$ always $)$. It contains the most important constituents of work holism. To measure the work holism questionnaire reliability in Agha Beigi research $84 \%$ was obtained via Kronbakh Alfa, also the test has been confirmed by masters and its convergence simultaneously with A type of behavior questionnaire which has given $61 \%$ correlation coefficient that shows the test reliability.

Kobasa's (1988) third generation of hardiness questionnaire: It contains 50 questions includes 17 questions about challenge, 16 questions about commitment and 17 questions about control that have been formed based on the Likert scale (4 options) which had an amplitude range from zero (incorrect) to 3 ( correct). The scores of 39 acts of the test are scored reversely and to each three subscales scores are presented separately and the non-weighted mean of these three subscales are accounted for the total score of the hardiness. Kobasa'shardiness test has been translated by Ghorbani (1995) and an acceptable content has been reported to it. Hardiness constituents as control, commitment and challenge have a reliability coefficient of $7 \%, 78 \%$ $72 \%$ respectively and the reliability for total hardiness was $15 \%$ ( Besharat, 2007). 
Table 1. Means, standard deviation, hardiness scores, its constituents and work holism.

\begin{tabular}{|c|c|c|}
\hline Variable & Mean & Standard deviation \\
\hline work holism & $68 / 175$ & $4 / 01$ \\
\hline commitment & $59 / 24$ & $4 / 18$ \\
\hline challenge & $58 / 31$ & $3 / 17$ \\
\hline control & $61 / 22$ & $4 / 11$ \\
\hline hardiness & $58 / 08$ & $4 / 19$ \\
\hline
\end{tabular}

Table 1 shows the mean and the standard deviation from hardiness and work holism scores in which the maximum mean relates to the control element by $61 / 22(4 / 11)$ value.

Table 2. The hardiness scores correlation coefficients, its constituents and work holism.

\begin{tabular}{|c|c|c|c|c|c|}
\hline Variable & $\begin{array}{c}\text { work } \\
\text { holism }\end{array}$ & commitment & challenge & control & hardiness \\
\hline work holism & 1 & $-0.549^{* * *}$ & $-0.380^{* *}$ & $-0.618^{* * *}$ & $-0.515^{* * *}$ \\
\hline commitmnt & & 1 & $0.953^{* * *}$ & $0.954^{* * *}$ & $0.954^{* * *}$ \\
\hline challenge & & & 1 & $0.895^{* * *}$ & $0.9 * * *$ \\
\hline control & & & & 1 & $0.921^{* * *}$ \\
\hline hardiness & & & & & 1 \\
\hline
\end{tabular}

Table 2 shows a significant and negative correlation among the hardiness constituents with work holism in male and female group of teachers. It also concluded that there is a negative relationship between hardiness and work holism that is the more the hardiness, the lower their work holism. So the research assumption is confirmed and zero assumption is rejected.

Table 3. Regression analysis to predict work holism based on the hardiness constituents.

\begin{tabular}{|c|c|c|c|}
\hline Variable & B & SEB & $\boldsymbol{\beta}$ \\
\hline work holism & $40.891^{* * *}$ & 2.270 & - \\
\hline commitment & -25.450 & 7.512 & $-0.711^{* * *}$ \\
\hline challenge & -32.778 & 5.075 & $-0.722^{* * *}$ \\
\hline control & -31.173 & 8.380 & $-0.531^{* * *}$ \\
\hline hardiness & -29.8 & 6.998 & $-0.654^{* * *}$ \\
\hline
\end{tabular}

Considering Table 3, the hardiness constituents can predict work holism. 
Table 4. Group differences in hardiness and work holism among male and female teachers.

\begin{tabular}{|c|c|c|c|c|c|c|}
\hline Variable & \multicolumn{2}{|c|}{ male } & \multicolumn{2}{c|}{ female } & df & t \\
\hline & Mean & Standarddeviation & Mean & Standarddeviatin & & \\
\hline hardines & 60.59 & 4.27 & 58.60 & 3.37 & 98 & 2.59 \\
\hline $\begin{array}{c}\text { work } \\
\text { holism }\end{array}$ & 67.14 & 3.16 & 69.21 & 4.86 & 98 & -2.52 \\
\hline
\end{tabular}

As it is shown in Table 4 and given the obtained $t$ scores there is a significant difference among male and female teachers' hardiness. That is the mean scores of hardiness among male teachers are higher than females. Also the obtained scores show a difference between male and female teacher's work holism, it means that in work holism difference variable, the male mean scores are higher than females.

Table 5. Group differences in hardiness and work holism among married and unmarried teachers.

\begin{tabular}{|c|c|c|c|c|c|c|}
\hline Variable & unmarried & & married & & df & $\mathbf{t}$ \\
\hline & Mean & $\begin{array}{c}\text { Standard } \\
\text { deviation }\end{array}$ & Mean & $\begin{array}{c}\text { Standard } \\
\text { deviation }\end{array}$ & & \\
\hline hardiness & 58.08 & 4.19 & 61.11 & 3.45 & 98 & -3.95 \\
\hline $\begin{array}{c}\text { work } \\
\text { holism }\end{array}$ & 67.33 & 4.11 & 69.02 & 3.91 & 98 & 2.10 \\
\hline
\end{tabular}

As it can be seen from Table 5 and regarding the obtained $t$ scores, there is a significant relationship among married and unmarried teachers in their hardiness; it means that the rate of hardiness and work holism among married teachers is more than unmarried ones.

\section{DISCUSSION}

Findings indicated that there is a negative and significant relationship between hardiness and work holism and the higher the hardiness, the lower the work holism and vice versa.

These results showed that people with hardiness are very resistant to the mental stress and they don't hurt mentally under the influence of the stressful situations (Kobasa and Madi; 1982). This research showed that hardiness has a negative correlation with drug and alcohol addiction whether in the past or present. In addition, this research results are consistent with the results from Brooks (2003) and Florian et al (1995) study about the positive relationship between hardiness and physical or mental health. Shaparandand Kashani (1999); Rash et al (1995) and Majidian (2004) about the negative relationship between hardiness and stress; King et al (1998) believes that people with hardiness evaluate the unsatisfying situations in a challenging manner not threateningly and they have more commitment about themselves and their work, also they experience more sense of control in their lives.

The results confirmed the previous findings by researchers such as Spence and Robins (1992), Asgari (2002), Jomhari (2002), Scott et al (1997) and Pitroswki - Vodanovich (2008). Therefore to validate this relationship, it can be point to the mediating role of hardiness in mental stress effects to create physical and mental disorders. Today, mental stress is served as 
a revealing indicator in mental disorders. It also has a significant role in some mental disorders such as anxiety. Other researches show that people with high rate of hardiness encounter stressful situations more effectively, for example by processing problems or converting situations to the positive ones. Moreover, these people are less involve in physical erosion in stressful conditions (Majidian, 2004). Of the other results was the hardiness difference among males and females, so that the rate of hardiness in males was more than females, Which is consistent with the findings of Ahadi et al (2008), Kobasa et al (1982).

With respect to the fact that women have more talent to depression (twice the men), hardiness is a resistant shield against it (Sheppard, Kashani 1999). It can be pointed that men are more involve in the internal elements in life events, while women are more involve in external elements. In addition, there is a significant relationship between hardiness and marriage status, as the rate of hardiness is higher in married people, which is consistent with the findings of Ahadi et al (2008).

This is probably originated from the fact that married people have more responsibilities comparing with unmarried ones. Most of them believe that they are not mainly belonging to themselves, but their families also are involved in their decisions and behaviors. It seems that they try to not serve the life events as boring and threatening and they usually try to make a dynamic life based on the exalted goal for themselves and their families. One other result was the difference between male and female as the rate of work holism in females was more than males that is not consistent (Snir and Harpaz; 2006). To confirm this, some believe that men are more involve in the internal elements, while women are more involve in the external elements of life events.

The leading theory conclude that the work holists accept some effects that are always enforcing, like admiration or criticism which cause to sustain behaviors relate to the work holism (Mc Milan et al 2003). One of the research limitations was the lack of a similar research in this area and relates to the topic in Iran and abroad; also this topic was new as there had been found no similar research in scientific-searching databases, so there was not enough background. One other limitation in the study was the use of usual samples (As they didn't consult to a consulting center and stated no complaint).

Also it was assumed that the work holist's performances on a continuum have many similarities in clinic and non-clinic populations. Anyway, the findings obtained from healthy samples should be considered remarkably to use this tool in other researches with clinic samples (they had consult to a center and stated a complaint). It is suggested that researchers examine the relationship between hardiness and work holism in occupational, industrial and trading groups. Also it can be useful to study a questionnaire with populations of various ages (teenagers, middle-aged and old); some workshops can be made to teach hardiness and being familiar with work holism to reduce work holism.

\section{CONCLUSION}

The institutions can be instructed to give consulting services or enough information to regulate work affairs to the extent that doesn't eliminate some of the life important activities. The results from this study have many applications in initial screening of the applicants in consulting pre-stages, especially to treat social, family and personal problems in clinical and researching environment. 


\section{Acknowledgment}

Researchers bound themselves to thanks all the directors and colleagues from Ghorveh High Schools and male and females who responded to the questionnaires.

\section{References}

[1] Besharat M. A., Journal of Psychological Studies 3(2) 2007 109-129.

[2] Ghorbani N., Journal of Psychological Research 3(4) (1995) 76-92.

[3] Agha Beigi L., Construction and customizing the work holism questionnaire for Tehran University masters. MA degree thesis. Psychological Department of Allame Tabatabai University, 2007.

[4] Ahadi M., Karbakhsh M., BaniJamali Sh. S., Hakimi Rad E., Journal of Psychological Studies 4(4) (2008) 95-112.

[5] Ahmadi P., Tahmasbi R., Baba Shahi J., Fatahi, M., Transformation Management Research 3 (2010) 46-67.

[6] Izkian SareShaban, Acomparison ofviolence and hardiness. MA thesis General Psychology, Tarbiat Moalem University, 2001.

[7] Jomhari F. Relationship Hardiness and tendency to anxiety and depression among male and female students of Tehran Universities. PHD thesis. The Psychological Department of Allame Tabatabai University, 2002.

[8] Sabri Nazarzadeh R., Abdkhodai, M. S., Contemporary Psychological Quarterly 5(1) (2010) 490-492.

[9] Asgari M., The relationship of hardiness and involvement with the addicting preparation. The MA thesis. The Psychological Department of Allameh Tabatabai University, 2002.

[10] Majidian F., The relationship of the self-efficacy beliefs and hardiness with the directorjob stress. The MA thesis. The Psychological Department of Allame Tabatabai University, 2004.

[11] Mohammad Talebi K., The relationship between the organizational culture and work holism. The MA thesis. The Psychological Department of Shahid Beheshti University, 2008.

[12] Nasiri A. The contemporary psychological seasonal publication 5(1) (2010) 761-763.

[13] Bandura A., Self-Efficacy: The exercise of control, New York: Freeman, 1997.

[14] Kobasa S. C., Maddi S. R., Kahn S., Journal of Personality and Social Psychology 42 (1982) 168-177.

[15] Kobassa S. C., Journal of personality and social psychology 37 (1979) 1-11.

[16] Kobassa S. C., Maddi S. R., Journal of health and social behavior 22(4) (1982) 368-378.

[17] Lambert V. A., International Nursing Review 54(1) (2007) 85-91. 
[18] Issacson B., Characteristics and enhancement of resiliency in young people. Research (MSc thesis), University of Wisconsin-stout, 2002.

[19] Maddi S. R., Kobassa S. C., Journal of Personality Assessment 63(2) (1994) 265-274.

[20] Maddi S. R., Kobassa S. C., Journal of performance studies 3 (1996) 35-40.

[21] Fergus S., Zemmerman M. A., Adolescent resilience: A framework for understanding healthy development in the face of risk. Proquest health and medical complete, 2005.

[22] Brooks M. V., Nursing Forum 38 (2003) 11-20.

[23] Florian V., Mikulincer M., Journal of Personality and Social Psychology (68) (1995) 687-695.

[24] Sheppard J. A., Kashani J. H, Journal of Personality 59(4) (1999) 747-767.

[25] Spence J. T., Robbins A. S., Journal of Personality Assessment 58(1) (1992) 160-178.

[26] Oates W., Confessions of a workaholic: The Facts about Work Addiction, World Publishing, New York, NY, 1971.

[27] McMillan L. H. W., O’Driscoll M. P., Burke R. J., International Review of Industrial and Organizational Psychology 18 (2003) 167-189.

[28] Buelens M., Poelmans S. A. Y., “Enriching the spence androbbins' typo- logy of work holism: Demographic, motivational and organizational correlates", Organizational Change Management, 2004, pp. 457-470.

[29] Snir R., Zohar D., Applied Psychology: An International Review 57(1) (2008) 109-127.

[30] Snir R., Harpaz I., Career Development International 11 (2006) No 5.

[31] Scott K. S., Moore K. S., Miceli M. P., Human Relations 50(3) (1997) 287-314.

[32] Piotrowski C., Vodanovich S., Journal of Instructional Psychology 35(1) (2008) $147-161$

[33] Schaufeli W. B., Bakker A., Van der Heijden F., Prins J., Work and Stress 23(2) (2009) $155-172$.

[34] King L. A., King D. W., Keane T. M., Faribank J. F., Adams G. A., Journal of Personality and Social Psychology 74(2) (1998) 420 - 434. 